\title{
The mandatory reporting of consensual, underage sex: Knowledge, practices and perspectives of social workers in KwaZulu-Natal
}

\author{
Z Essack ${ }^{1,2}$ BSocSci (Psyc), BSocSci (Hons), MSocSci (Research Psychology), PhD; A Strode, ${ }^{2}$ BA, LLB, LLM, PhD \\ ${ }^{1}$ KwaZulu-Natal Legislature, KwaZulu-Natal, South Africa \\ ${ }^{2}$ School of Law, University of KwaZulu-Natal, Pietermaritzburg, Durban, South Africa
}

Corresponding author:Zaynab Essack (zaynab.essack@gmail.com)

\begin{abstract}
Until recently, any sex or sexual activity with a person under the age of 16 was criminalised, regardless of consent. All such incidents were considered criminal offences and needed to be reported to the police. This paper explores the knowledge, practices and perspectives of seventeen social workers in KwaZulu-Natal in relation to their mandatory reporting responsibilities on consensual underage sex. All social workers were clear about their reporting responsibilities regarding child abuse and non-consensual underage sex. However, findings suggest that social workers were less clear on the exact circumstances in which they ought to report consensual underage sex. Most participants indicated that they would make individual assessments about when to report underage consensual sex and sexual activity. Such decisions would be influenced by structural factors, the personal circumstances of affected children and the availability of other interventions to address early sexual activity. This study has shown that social workers are struggling to comply with mandatory reporting responsibilities involving underage consensual sex. Most social workers approach reporting of consensual sex and sexual activity differently to other reporting responsibilities and use a case-by-case approach. Given these findings, it is argued that parliament should consider reforming mandatory reporting provisions so that there is a distinction between the obligation to report consensual and non-consensual sexual offences against children. The mandatory obligation to report non-consensual sexual offences against children should remain but the obligation to report consensual sex or sexual activity should be discretionary and depend on the facts of each case.
\end{abstract}

S Afr J BL 2015;8(2):21-25. DOI:10.7196/SAJBL.435

Until recently, any sex (penetrative intercourse) or sexual activity (e.g. kissing, petting or hugging) with a person under the age of 16 was criminalised, regardless of consent. ${ }^{[1]}$ All such incidents were considered criminal offences and needed to be reported to the police. ${ }^{[2]}$ Despite these laws, many South African (SA) adolescents are engaging in consensual underage sex as evidenced by high rates of teenage pregnancy. For example, 36702 school goers were pregnant in 2010. ${ }^{[3]}$ Recent research in SA found that 'many young adolescents are engaging in a variety of sexual behaviours ranging from kissing and touching to intercourse. ${ }^{\text {[4] }}$

Sections 15 and 16 of the Criminal Law [Sexual Offences and Related Matters] Amendment Act ${ }^{[1]}$ (hereafter the 'Sexual Offences Act'), which criminalised underage consensual sex and sexual activity have been extensively criticised. Commentators contended that criminalising consensual underage sex is incongruent with developmentally normative sexual practices among adolescents, ${ }^{[4-5]}$ is incompatible with other legislation like the Children's Act and the Choice of Termination of Pregnancy Act, ${ }^{[6-7]}$ contrary to the principle of 'the best interests of the child' and inconsistent with children's constitutional rights to bodily and psychological integrity and privacy ${ }^{[6]} \mathrm{A}$ further criticism of the Sexual Offences Act was that it made it incumbent on all service providers, including doctors, social workers, psychologists and others to report consensual underage sex to a police official. This places practitioners'in an invidious position' since client-provider relationships are founded on the principle of confidentiality. ${ }^{[5]}$ Although the law had been in place for more than 5 years, few studies have detailed service providers' experiences with fulfilling their mandatory reporting responsibilities. Much of the international literature has focussed on the mandatory reporting of child abuse, including perspectives of service providers. ${ }^{[8.9]}$

This paper is based on a qualitative study involving social workers and explores their knowledge, practices and perspectives on children's evolving sexual and reproductive rights, including mandatory reporting responsibilities. The Constitutional Court recently found the criminalisation of consensual peer-group sex and sexual activity to be inconsistent with the constitution as it violated the rights of children. ${ }^{[10-11]}$ Resultantly, sections 15 and 16 of the Sexual Offences Act were referred to parliament for amendment. ${ }^{[10]}$ This article is timely as the recent decriminalisation of consensual underage sex has implications for mandatory reporting responsibilities and only presents study findings regarding the mandatory reporting of underage consensual sex.

\section{The legal framework: The age of consent to sex and accompanying mandatory reporting responsibilities Legal position prior to decriminalisation of consensual underage sex by the Constitutional Court}

The Sexual Offences Act sets the age of consent to sex at $16 .{ }^{[1]}$ Below the age of 12, the Act provides that children do not have the capacity to consent to sex and therefore any sexual activity with a person below this age amounted to rape. ${ }^{[1]} \mathrm{A}$ child aged 12 to 16 could consent to sex; 
however, the sexual act or activity was criminalised. ${ }^{[2]}$ Furthermore, the Act mandated the reporting of all sexual offences against children to the police with section 54(1) stating any person 'who has knowledge that a sexual offence has been committed against a child' must report this 'immediately' to the police; failure to comply with this obligation was an offence. ${ }^{[1]}$ This included consensual sexual encounters.

\section{Situation following decriminalisation of consensual underage sex by the Constitutional Court}

The Constitutional Court found that sections 15 and 16 of the Sexual Offences Act violated a child's rights to privacy and dignity and was not in their best interests. ${ }^{[10]}$ It declared the sections invalid but suspended the declaration of invalidity for 18 months to allow parliament to rectify the constitutional defects in the Act. ${ }^{[10]}$ In the interim, the court placed a moratorium on all arrests and prosecutions of teenagers aged 12 - 16 who engaged in consensual peer-group sex or sexual activity. ${ }^{[10]}$ The judgment also narrowed the scope of mandatory reporting requirements in this interim period to consensual sex or sexual activity with children under the age of 12 , and where one of the participants is aged $12-15$ and the other is older than $166^{[2,12]}$

The National Assembly recently issued an amendment of sections 15 and 16 of the Sexual Offences Act in the form of the Sexual Offences Amendment Act Amendment Act (No 5 of 2015), which was signed into law in July $2015^{[13]}$ (hereafter the 'amendment'). In line with the Constitutional Court ruling, the amendment decriminalises all consensual sex or sexual activity between children aged 12 - 15; and when one partner is $16 / 17$ and the other is $12-15$, as long as there is no more than a two-year age difference between them. ${ }^{[13]}$ This means that for example, if one child is 12 and the other is 16 , consensual sex between them remains criminalised as there is more than a two-year age gap between them. It also remains a reportable sexual offence. ${ }^{[1]}$

\section{Methodology}

\section{Sample and procedure}

Semi-structured interviews were conducted with 17 social workers across various districts in KwaZulu-Natal. Face-to-face interviews were conducted with 13 social workers and telephone interviews with an additional four. Except for the loss of ability to access social cues (e.g. body language) and the poor quality of telephone reception in one interview, telephone interviews provided data comparable to face-toface interviews. Interviews lasted 45 minutes to an hour.

Participants were purposively sampled based on their involvement in the care of children. Data were collected between November 2013 and January 2014. All participants provided their informed consent for interviews. Ethical approval for this study was obtained from the University of KwaZulu-Natal's Human and Social Sciences Ethics Committee (HSS/0945/013).

Social workers' practices and perspectives were thematically analysed. ${ }^{[14]}$ Key themes were developed inductively by listening to audio-recorded interviews and summarising each interview. Emerging issues of relevance to the research questions were identified and portions of the interview that illustrated these issues were transcribed verbatim. ${ }^{[15]}$ These emerging issues informed the development of a coding framework, which was refined in team discussions. Transcripts and summaries were coded according to this framework on QSR NVIVO 10 (a qualitative software package).

\section{Findings}

This section describes the knowledge, practices and perspectives of social workers in relation to their mandatory reporting of underage consensual sex.

\section{Knowledge of reporting responsibilities}

All participants reported knowledge of mandatory reporting responsibilities in relation to abuse and underage non-consensual sex. Reporting of child abuse was considered unequivocal and all participants exercised their legal responsibilities in this regard. However, many participants were less clear about reporting underage consensual sex. For example: 'I don't really know how the law works regarding consensual underage sex...' (P10). This uncertainty about their legal reporting responsibilities was reflected in their lack of understanding of who is responsible for reporting and to whom. One respondent noted that she would seek guidance from her supervisor regarding whether to report such cases. Some assumed that reporting consensual underage sex to police was the parent's prerogative and described informing parents of their responsibility. For example:

'The only [thing] that I do, I consult the family member, 'cause I feel that they are the ones who are responsible. As social workers we are also responsible but since there is a family member, who can be responsible for the child, let that person be responsible.' (P9)

'I encourage caregivers to open up cases.' (P14)

Only a few participants were aware of changes to the law regarding consensual underage sex and consensual sexual activity.

\section{Reporting practices regarding underage consensual sex}

Few participants reported having experience with reporting consensual underage sex to a police officer. For example:

\section{$R:$ 'Why do you prefer not to report to SAPS?'}

P9: 'I don't know, I felt I didn't want to take the responsibility. I don't want to take the responsibility in those cases 'cause as I said if there is a family member, the only thing I can do is report that something is happening ... I don't know if I have to do it or I don't have to do it but I've never done it ... unless maybe there is a paper that could say these are the things that we have to do as a social worker if you get such cases. Then I'll be able to do it. And I'll know when I get to the police station, who I'll ask for because they are also not aware of these things.'

Instead, children engaging in consensual underage sex were offered counselling and referral to other services:

'Sometimes we get the cases whereby children who were schooling together, maybe they were having sort of sex or videotaping whereby the other one is naked ... we do the counselling with them and refer them to the Child Line.' (P7)

I had a case yesterday. The mother of the child came. The child was 5 months pregnant, she's 14 years old. The boyfriend is 16. Apparently the mother doesn't want to open a case of rape but the father is saying its rape. So the child is saying the boyfriend didn't rape her. So I just didn't know what to do... I took the child in and offered counselling services to the child. And I asked her does she want to continue seeing me for 
counselling services and she said no. So I found out from her did the boy rape you, she said no. Do you want to open a case, "no l agreed to having sex with my boyfriend"'.(P11)

'I think that we just need to give them [the children] proper counselling...' (P15)

\section{Factors influencing reporting decisions}

While only a few participants had experience with reporting underage consensual sex to police, all participants were asked for their views on the appropriate actions in such circumstances. They were also asked to reflect on the factors that would influence their reporting choices. Some social workers reported that they would always report underage consensual sex:

'Yes ... it needs to be reported. It's not something that they have to do. They are not married, they are not adults.' (P1)

$\therefore$...need to report so that maybe the one who do these things can be afraid of these police.' (P5)

However, many said that they would consider several factors in making reporting decisions. Some social workers perceived the age difference of minors as being important in determining to whom such cases should be reported. When the age difference was negligible, approaching parents was preferred, but where the age difference was significant, reporting to the police was deemed appropriate. For example:

'When children are 10/11 then I would go to the parents but where a child is 11 and 16 I would normally go to the police.' (P8)

Others noted the potential trauma of children having to endure the criminal justice system and the psychological ramifications of being entered onto the Sexual Offences Register as being important factors when deciding whether to report:

...because they are in a relationship in their own way. There is nobody who has forced anyone... you just need to give them guidance and equip them with the necessary skills to deal with that ... I don't think it would help if you just send those children for criminal charges. I don't think it would help them in any way. ... if you put an element of criminality now, it's going to even traumatise the child further.' (P15)

Children being in a 'love relationship' seemed to influence the social workers' approach in favour of offering counselling and other programmes rather than criminalisation: '... they must get some programmes, both of them ... because they say they are in a love relationship.' (P4)

Perceptions of the futility of reporting also deterred social workers from reporting. They considered that cases of underage consensual sex are unlikely to proceed since the implicated minors would be reluctant to report and/or testify. For example:

....there was two cases by the parent to two different social workers one was 16 and the other 15 years. The social workers did counselling, followed the protocol, the children refused. One was examined; the doctor confirmed penetration. But they said they are not going to go to court as they feel they are in a relationship.... We term these cases statutory rape but if the girl does not want to testify we cannot go to court. One of the girls refused to testify, she went missing. So there are a lot of challenges.' (P2)

A few participants regarded the manner in which cases are processed in the justice system as being a deterrent to reporting consensual underage sex. It was noted that some South African Police Services (SAPS) officers are themselves reluctant to open cases because often prosecutors decline to proceed with the matter and simply return these cases to social workers. For example:

'Yes I have [previously reported consensual underage sex]. The girl was 16 she was "gang raped" by three men but she kept saying it was consensual and I asked her how it was consensual, you can't have sex with three men, but we have no idea of the case developments. I find it frustrating to deal with such cases because the courts toss them back to you so I get the families together.' (P8)

'Most of the cases the perpetrators have not been prosecuted ... never, never, never.' (P17)

Finally, the opinion of the parents was a consideration, with some suggesting that socio-cultural taboos may deter parents from reporting consensual underage sex to the authorities. For example:

'We don't get a lot of support from the parents sometimes. Like they don't want to open cases.' (P12)

'It becomes a challenge in such cases because even though the elders/ the adults in the families are aware, they will try not to report the matter 'cause it's like taboo or something ... it should be kept in the family. Pay or slaughter a goat or something...'(P13)

\section{Awareness of penalties for failing to report}

The Sexual Offences Act stipulates that any person failing to comply with the obligation to report knowledge of a sexual offence committed against a child, commits an offence and may be sentenced to a fine or a maximum of 5 years in prison or both. ${ }^{[1]}$ Awareness of this penalty among participants was variable. Some reported not being explicitly aware of the penalty: 'I haven't heard of anything.' (P14) Some assumed that a penalty may be likely for failing to report. For example:

'Because I would have put maybe a child's life in danger by not reporting so I think there would be disciplinary measures... But none that I've been trained or informed of.' (P10)

A few participants were aware of the penalty because of information from supervisors, or their knowledge of various Acts. For example:

'It's in the Children's Act, you have to report... I do know it's a criminal offence and I will be charged for it because I'm hiding something that may harm the child, so why am I not reporting? So I do know. What charges that might be imposed on me, I'm not sure but I do know that it's a criminal charge.' (P12)

'I know. One is you can be found guilty of an offence if you knew about the case and you just kept quiet and didn't report.'(P16)

\section{Discussion}

This article explored the knowledge, practices and perspectives of social workers in relation to their mandatory reporting responsibilities 
on consensual underage sex. Given their central involvement with children and families, social workers are ideally positioned to intervene on behalf of children and also to advocate for their wellbeing, welfare and protection.

All social workers were clear about their mandatory reporting responsibilities regarding child abuse. However, findings suggest that social workers were less clear on the exact circumstances in which they ought to report consensual underage sex. There were also low levels of compliance in terms of reporting all cases of underage consensual sex to the SAPS. Table 1 below outlines mandatory reporting obligations according to the amended Act. ${ }^{[13]}$

Despite legal requirements, most participants indicated that they would make individual assessments about when to report underage consensual sex and sexual activity. These findings resonate with research conducted with healthcare providers. ${ }^{[16]}$ Few healthcare providers fulfilled their mandatory reporting responsibilities. Decisions to report were influenced by factors such as a patient's age, the consequences of reporting and the impact on confidentiality. ${ }^{[16]}$

Factors considered to influence reporting decisions in this study can be clustered in three main categories:

- Structural factors related to perceptions that police are dismissive of consensual underage sex cases, and that even when these cases are reported to police they are ultimately reverted to social workers.
Therefore reporting was considered a futile exercise that may unnecessarily burden the justice system.

- The personal circumstances of the affected children including their age, the age differences between children, and whether they claimed to be in a loving, consensual relationship would inform reporting decisions. This more flexible approach resonates with some factors outlined in the Children's Act in terms of applying the 'best interests of the child' principle, including considering'the child's age, maturity and stage of development, gender, background and any other relevant characteristic of the child' ${ }^{[11]}$ Sensitivity to personal circumstances also indicates cognisance that consensual sexual exploration among adolescents is developmentally normative. ${ }^{[4]}$ Age difference was one of several factors considered by social workers in this study when deciding whether to report consensual underage sex. This is contrary to the approach in the recently amended Act $^{[13]}$ which makes age difference the sole factor guiding whether the behaviour will attract criminal sanction.

- Social workers considered the availability of other interventions to address early sexual activity, such as counselling or the involvement of parents. Such interventions were favoured given concerns that reporting to the police may result in children being inappropriately exposed to the criminal justice system, which may result in psychological harm.

Table 1. Mandatory reporting obligations of service providers in relation to the Sexual Offences Amendment Act Amendment Act ${ }^{[13]}$

\begin{tabular}{llll}
\hline & & $\begin{array}{l}\text { Consensual sex/sexual activity: } \\
\text { legal }(\sqrt{ })\end{array}$ & \\
Age of A & Age of $\mathbf{B}$ & illegal $(\times)$ & $\begin{array}{l}\text { Reporting } \\
\text { responsibilities }\end{array}$ \\
\hline If either participant is below 12 years & Rape & Report \\
Any age & & Non-consensual & Report \\
$12,13,14$ or 15 & $12,13,14$ or 15 & $\sqrt{ }$ & Do not report \\
12 & 16 & $\times$ & Report \\
12 & 17 & $\times$ & Report \\
13 & 16 & $\times$ & Report \\
13 & 17 & $\times$ & Report \\
14 & 16 & $\sqrt{ }$ & Do not report \\
14 & 17 & $\times$ & Report \\
15 & 16 & $\sqrt{ }$ & Do not report \\
15 & 17 & $\sqrt{ }$ & Do not report
\end{tabular}

These perceptions resonate with recent Constitutional Court findings that we must be mindful of the long-term implications of actions we take against children as they have a right to 'learn as they grow how they should conduct themselves and make choices in the wide and moral world of adulthood! ${ }^{[17]}$ The court found that the age of consent should remain at 16 , however this norm should not be enforced through criminalising underage consensual sex. ${ }^{[10]}$ Furthermore, compounding the immense stigma and shame associated with being convicted of a sexual offence are the negative impacts on future work prospects, including that offenders are prohibited from working with children. ${ }^{[5,17]}$

Finally as with healthcare providers, ${ }^{[16]}$ confidentiality is a guiding principle of social work practice, and sometimes reporting information disclosed confidentially may undermine trust in the social worker-client relationship. ${ }^{[1]]}$

Of the social workers who had experience with cases of underage consensual sex, only a few opted to report to authorities for the reasons outlined above. However, none of the participants in this study described experiencing any disciplinary or legal penalty for not complying with their mandatory responsibilities, which suggests that this law may be difficult to enforce. It also calls into question whether the rigidity of the mandatory reporting responsibilities are achieving their purpose of protecting child victims of sexual offences.

Given the small sample size, the practices and perspectives presented here may not be representative of all social workers in KwaZulu-Natal or SA more broadly. Nevertheless, it is possible to argue that the issues raised by the sample might be identified in the general context of social work practice vis-à-vis mandatory reporting responsibilities.

\section{Conclusions}

Although the issue of criminalising consensual underage sex was recently before the Constitutional Court it was never argued in this case that the overly broad mandatory reporting provisions were inconsistent with the constitution but rather that the impact of criminalising consensual underage sex was heightened by them.$^{[10]}$ In other words the Constitutional Court was not asked to 
consider whether the mandatory reporting responsibilities violated children's constitutional rights. Nevertheless, the amendments do narrow the reporting obligations of service providers in terms of consensual underage sex. However, they do not completely absolve providers of their mandatory reporting duties (see Table 1), which may still present complex ethical conflicts for providers, as detailed elsewhere. ${ }^{[2]}$

This study has shown that social workers are struggling to comply with reporting responsibilities involving underage consensual sex. Most social workers approach reporting of consensual sex and sexual activity differently to other reporting responsibilities and use a case-by-case approach. Given this context, it is argued that parliament should consider reforming section 54 of the Sexual Offences $\operatorname{Act}^{[11]}$ so that there is a distinction between the obligation to report consensual and non-consensual sexual offences against children. The mandatory obligation to report non-consensual sexual offences against children should remain but the obligation to report consensual sex or sexual activity should be discretionary and depend on the facts of each case. Furthermore, detailed training should be provided to social workers and other service providers to enable them to apply the recent changes in the law.

Acknowledgements. This study was undertaken as part of the oversight activities of the Social Development Portfolio Committee at the KwaZulu-Natal Legislature. The views expressed in this paper do not necessarily reflect those of the Social Development Portfolio Committee or the KwaZulu-Natal Legislature. Thanks are extended to Ms Jacintha Toohey for her assistance with data collection. Sincere thanks go to all the respondents who participated in interviews and to Dr Ngcongo of the Department of Social Development for assistance with access to social workers.

\section{References}

1. Republic of South Africa. Criminal Law (Sexual Offences and Related Matters) Amendment Act No. 32 of 2007. Pretoria: Government Printer 2007.
2. Strode A, Toohey J, Slack C, et al. Reporting underage consensual sex after the Teddy Bear case: A different perspective. S Afr J Bioeth Law 2013;6(2): 45-47. [http://dx.doi.org/10.7196/sajbl.289]

3. Department of Basic Education. Annual School Surveys: Report for Ordinary Schools 2010 and 2011. South Africa: Department of Education, 2013. http://www.google.co.za/url? sa $=t \& r c t=j \& q=\& e s r c=s \& f r m=1 \&$ source $=w$ eb\&cd $=1$ \&ved =0CCgQFjAA\&url=http $\% 3$ A\%2F\%2Fwww.education.gov. za\%2FLinkClick.aspx\%3Ffileticket\%3D8mBPHBmAGY0\%253D\%26tabid\%3D3 6\%26mid\%3D2514\&ei=G8lyU-3CGYS6ygP14LYAg\&usg=AFQjCNFRTILXj12HW zSTFIH0qjEjCHcfww\&sig2=vSZHrVN6431GSPWI9TpgSA\&bvm=bv.63738703,d. bGQDownloadFileAction?id=67892 (accessed 11 November 2014).

4. Gevers A, Mathews C, Cupp P, et al. Illegal yet developmentally normative: A descriptive analysis of young, urban adolescents' dating and sexual behaviour in Cape Town, South Africa. BMC Int Health Hum Rights 2013;13(1):31. http://www.biomedcentral.com/ content/pdf/1472-698x-13-31.pdf (accessed 23 November 2014).

5. Perumal D. Misguided reform: Regulating consensual sexual activity between adolescents in South African law from a gender perspective. Agenda 2013;27(3):107-117. [http://.dx.doi.org/10.1080/10130950.2013.849789]

6. McQuoid-Mason D. Decriminalisation of consensual sexual conduct between children: What should doctors do regarding the reporting of sexual offences under the Sexual Offences Act until the Constitutional Court confirms the judgment of the Teddy Bear Clinic case? S Afr J Bioeth Law 2013;6(1):10-12. [http://dx.doi.org/10.7196/SAJBL.257]

7. Strode A, Slack C, Essack Z. Child consent in South African law: Implications for researchers, service providers and policy-makers. S Afr Med J 2010;100(4):247-249.

8. Delaronde S, King G, Bendel R, Reece R. Opinions among mandated reporters toward child maltreatment reporting policies. Child Abuse Negl 2000; 24(7):901910. [http://dx.doi.org/10.1016/S0145-2134(00)00151-4]

9. Savell S. Child sexual abuse: Are health care providers looking the other way? J Forensic Nurs 2005;1(2):78-82. [http://dx.doi.org/.10.1111/j.1939-3938.2005.tb00018.x]

10. Teddy Bear Clinic for Abused Children and Another v. Minister of Justice and Constitutional Development and Another [2013] ZACC 35

11. Mahery P. Reporting sexual offences involving child patients: What is the current law following the Constitutional Court judgement? S Afr J Bioeth Law 2014;7(1):26 -29.[http://dx.doi.org/10.7196/sajbl.303]

12. McQuoid-Mason DJ. The Teddy Bear Clinic Constitutional Court case: Sexual conduct between adolescent consenting children aged under 16 years decriminalised and a moratorium on the reporting duties of doctors and others. S Afr Med J 2014;104(4):275-275. [http://dx.doi.org/10.7196/SAMJ.7653]

13. Republic of South Africa. Criminal Law (Sexual Offences and Related Matters) Amendment Act Amendment Act, No 5 of 2015. Pretoria: Government Printer 2015. http://pmg-assets.s3website-eu-west-1.amazonaws.com/38977_7-7_Act5of2015CriminalLaw_a.pdf (accessed 10 July 2015).

14. Braun V, Clarke V. Using thematic analysis in psychology. Qual Res Psychol 2006;3(2):77-101. [http://dx.doi.org/10.1191/1478088706qp063oa]

15. Silverman D. Doing qualitative research: A practical handbook. 2nd ed. London: Sage Publications. 2005.

16. Hoffman-Wanderer Y, Carmody L, Chai J, Röhrs S. Condoms? Yes! Sex? No! Conflicting responsibilities for healthcare professionals under South Africa's framework on reproductive rights. University of Cape Town:The Gender, Health \& Justice Research Unit. 2013. http:// www.ghjru.uct.ac.za/pdf/Condoms_Yes_Sex_No.pdf (accessed 18 February 2015).

17. J v. National Director of Public Prosecutions and Another 2014 (7) BCLR 764 (CC). 